\title{
Feasibility and challenges of using multiple breath washout in COPD
}

This article was published in the following Dove Press journal: International Journal of COPD

\author{
Alan S Bell',2 \\ Philip J Lawrence' \\ Dave Singh ${ }^{1-3}$ \\ Alexander Horsley ${ }^{2-4}$ \\ 'The Medicines Evaluation Unit, \\ Wythenshawe Hospital, Manchester, \\ UK; ${ }^{2}$ Division of Infection Immunity \\ and Respiratory Medicine, Faculty \\ of Biology Medicine and Health, \\ University of Manchester, Manchester, \\ UK; ${ }^{3}$ Manchester Academic Health \\ Science Centre, Manchester, UK; \\ ${ }^{4}$ Manchester Adult Cystic Fibrosis \\ Centre, Manchester University NHS \\ Foundation Trust, Manchester, UK
}

Correspondence: Alexander Horsley Division of Infection Immunity and Respiratory Medicine, Faculty of Biology Medicine and Health, Education and Research Centre, University of Manchester, Floats Road, Manchester M23 9LT, UK

Email alexander.horsley@

manchester.ac.uk
Background: Lung clearance index (LCI), derived from multiple-breath washout (MBW), is a well-established assessment of ventilation inhomogeneity in cystic fibrosis but has not been widely applied in other conditions characterized by heterogeneous airways disease, such as COPD. The aim of this study was to evaluate the sensitivity, repeatability, and practicality of LCI in patients with COPD.

Methods: Fifty-four COPD patients completed MBW using nitrogen as the washout tracer gas $\left(\mathrm{MBW}_{\mathrm{N} 2}\right.$, measured using an Exhalyzer ${ }^{\mathrm{TM}}$ device), spirometry, and plethysmography. Twenty patients repeated $\mathrm{MBW}_{\mathrm{N} 2}, \mathrm{MBW}_{\mathrm{SF} 6}$ (using a separate Innocor ${ }^{\mathrm{TM}}$ gas analyzer to measure washout of the exogenous trace sulphur hexafluoride), and spirometry at a second visit $\geq 24$ hours later. Results: Mean (SD) COPD LCI measured by nitrogen washout $\left(\mathrm{LCI}_{\mathrm{N} 2}\right)$ was 12.1 (2.2); mean (SD) LCI Z-score 5.8 (2.0). LCI $_{\mathrm{N} 2}$ increased across Global Initiative for Obstructive Lung Disease stages 1 to 3 and was abnormal (Z-score $>1.65$ ) in all COPD patients, including those with forced expiratory volume in 1 second $\left(\mathrm{FEV}_{1}\right) \geq 80 \%$ predicted. LCI was repeatable (median intra-test coefficient of variation $4.1 \%$ ) and reproducible (limits of agreement -1.8 to 1.6) after mean of 16 days. Functional residual capacity (FRC) measurements were significantly greater using nitrogen than $\mathrm{SF}_{6}$ or plethysmography: mean $\mathrm{FRC}$ measured by nitrogen washout $\left(\mathrm{FRC}_{\mathrm{N} 2}\right)$ $139 \%$ predicted versus FRC measured by plethysmography $125 \%$ predicted, $p<0.0001$.

Conclusion: LCI is most suitable as a measure of early airways disease in COPD in those with well-preserved $\mathrm{FEV}_{1}$, with similar repeatability and limitations to that observed in cystic fibrosis. Using the Exhalyzer system to perform $\mathrm{MBW}_{\mathrm{N} 2}$, however, appeared to substantially over-read FRC. This discrepancy needs addressing before $\mathrm{FRC}_{\mathrm{N} 2}$ measurements made using this device can be reliably deployed.

Keywords: COPD, multiple breath washout, lung volumes, lung physiology, functional residual capacity, lung clearance index

\section{Introduction}

Multiple-breath washout (MBW) testing is now well established in cystic fibrosis (CF) research as a practical and reproducible measure of airways physiology that is both more sensitive at detecting the presence of disease and at monitoring treatment responses compared with conventional spirometry. ${ }^{1} \mathrm{MBW}$ involves tidal breathing to wash an inert tracer gas from the lungs and generates measures of lung volume (functional residual capacity; FRC) as well as of gas mixing efficiency. ${ }^{2}$ The most important and commonly reported outcome is the lung clearance index (LCI), a summary measure of ventilation heterogeneity. It has been known for some time that COPD results in abnormal gas mixing, ${ }^{3}$ and also that ventilation heterogeneity is an early feature of smokingrelated lung disease. ${ }^{4}$ Ventilation heterogeneity has been demonstrated in COPD using ventilation-MRI, and seems to relate to other measures of disease severity. ${ }^{5}$ However, 
the applicability of current MBW technologies for measuring ventilation heterogeneity in COPD has not been studied.

The European CF Society have recently published recommendations for use of $\mathrm{MBW}$ in clinical trials in $\mathrm{CF}^{6}$ and there is a drive for clinical application of these measurements. ${ }^{7}$ MBW is now available in several CF centers in the US and Europe, the majority using nitrogen washout systems, which derive nitrogen concentration from measurements of expired $\mathrm{O}_{2}$ and $\mathrm{CO}_{2}$. Nitrogen washout is performed by breathing $100 \%$ oxygen. This differs from the majority of recent formative $\mathrm{MBW}$ studies where $\mathrm{SF}_{6}$ was used as the tracer gas, with washout by breathing room air. Different technologies seem to deliver different measures of LCI and FRC, ${ }^{8}$ and these are not interchangeable even between nitrogen washout systems. ${ }^{9}$

The role of $\mathrm{MBW}$ in COPD may differ from that in $\mathrm{CF}$, being potentially more relevant in disease phenotyping and assessing treatment response than in detecting and preventing early disease progression. For MBW to be adopted in this way, it must be sensitive to disease identification, practical to perform, ${ }^{10}$ and reproducible. ${ }^{11}$ The applicability of MBW in adults with COPD has not previously been assessed.

We hypothesized that MBW would be a practical, repeatable, and potentially informative test in adults with COPD. The aims of this study were, therefore, as follows:

1. To assess practical limitations of MBW in patients diagnosed with COPD, including test time and success rates.

2. To assess intra-visit repeatability and inter-visit reproducibility of LCI and FRC.

3. To compare MBW outcomes with other lung function measures in patients diagnosed with COPD.

4. To compare indices from nitrogen washout with those from $\mathrm{SF}_{6}$ washout.

\section{Materials and methods}

This study was performed at the Medicines Evaluation Unit, University Hospital of South Manchester, UK. COPD patients were aged $>40$ years and had a diagnosis of COPD in accordance with the 2013 Global Initiative for Obstructive Lung Disease (GOLD) recommendations. ${ }^{12}$ This included a smoking history $\geq 10$ pack-years with typical symptoms ( 1 or more of productive cough, breathlessness, and wheeze) and evidence of airflow obstruction (forced expiratory volume in 1 second $\left[\mathrm{FEV}_{1}\right] /$ forced vital capacity $\left.<0.7\right)$. Additional exclusion criteria included any respiratory tract infection or COPD exacerbations within 6 weeks of assessment.

Patients diagnosed with COPD continued all regular pharmacological therapies but restricted short-acting inhaled bronchodilators for a minimum of 8 hours, and long-acting inhaled bronchodilators for a minimum of 24 hours prior to assessments. The study was approved by the Greater Manchester South research ethics committee (reference: 10/H1003/108) and written informed consent was obtained from each subject.

\section{Study design}

Fifty-four patients diagnosed with COPD performed impulse oscillometry, MBW, gas transfer, whole-body plethysmography, spirometry, and a 6-minute walk test (6MWT) of exercise capacity (in that order). Subjects were invited to return for repeat MBW testing $>24$ hours later.

\section{Assessments}

Detailed descriptions of each of the measurements can be found in the online supplement. Multiple-breath nitrogen washout $\left(\mathrm{MBW}_{\mathrm{N} 2}\right)$ was performed as previously described ${ }^{8}$ using an open circuit, bias flow system (Exhalyzer D ${ }^{\circledR}$, EcoMedics AG, Duernten, Switzerland). Analysis was performed using the associated software (Spiroware 3.1 EcoMedics AG). $\mathrm{MBW}_{\mathrm{N} 2}$ was performed 3 times and reported values for FRC measured by nitrogen washout $\left(\mathrm{FRC}_{\mathrm{N} 2}\right)$ and LCI measured by nitrogen washout $\left(\mathrm{LCI}_{\mathrm{N} 2}\right)$ are the average of at least 2 reproducible repeats. Age-matched Z-scores for $\mathrm{LCI}_{\mathrm{N} 2}$ were taken from those provided by the manufacturers.

A subset of patients performed additional $\mathrm{MBW}$ of $\mathrm{SF}_{6}$ $\left(\mathrm{MBW}_{\mathrm{SF} 6}\right)$. This was carried out using an open circuit washin of $0.2 \% \mathrm{SF}_{6}$ followed by washout breathing room air, using a modified Innocor analyzer as previously described. ${ }^{13}$ Both $\mathrm{MBW}_{\mathrm{N} 2}$ and $\mathrm{MBW}_{\mathrm{SF} 6}$ were performed according to consensus recommendations. ${ }^{14}$

Spirometry was performed according to the American Thoracic Society/European Respiratory Society recommendations ${ }^{15}$ using a Sensormedics Vmax spirometer (Sensormedics Corporation, Yorba Linda, CA, USA). Reference values used were those of the 2012 Global Lung Initiative. ${ }^{16}$

Impulse oscillometry was performed using a Masterscreen impulse oscillometer (IOS; Erich Jaeger, Hoechenberg, Germany) in accordance with consensus recommendations. ${ }^{17}$ Plethysmographic lung volumes were measured in accordance with the American Thoracic Society/European Respiratory Society recommendations ${ }^{16}$ using a constant volume whole-body plethysmograph (Autobox 6200 DL, Sensormedics Corporation). Carbon monoxide diffusing capacity $\left(\mathrm{DL}_{\mathrm{CO}}\right)$ and carbon monoxide transfer coefficient $\left(\mathrm{K}_{\mathrm{CO}}\right)$ were measured using the Vmax 22 instrument (Sensormedics Corporation), according to ATS/ERS recommendations. ${ }^{18}$ The reported value is the mean of at least 2 successful 
readings within $10 \%$ of the highest value. The $6 \mathrm{MWT}$ test was conducted to a standardized protocol in accordance with current guidelines using a 20 -meter course. ${ }^{19}$

\section{Statistical analysis}

A sample size of 10 patients would give $99 \%$ power to detect a $20 \%$ difference in LCI over historical control data and a sample size of 22 would be required to detect a $10 \%$ difference in LCI. We were interested, however, in how LCI compared with lung physiology across a range of disease severity and estimated that 50 patients would be sufficient to make reasonable inferences about how airway markers compared, and would give us enough subjects to get repeat LCI measurements on at least 20.

Data were analyzed using Prism (GraphPad Software Inc., San Diego, CA, USA). Parametric data were expressed as mean (SD) and non-parametric data expressed as median with interquartile range (IQR). For comparison of physiology parameters with GOLD stage, a 1-way analysis of variance was conducted, followed by Tukey's multiple comparison test to compare pairs of data. Correlations were assessed using a Pearson's correlation coefficient or a Spearman's rank correlation coefficient. Intra-visit repeatability was determined by calculating the coefficient of variation $(\mathrm{CV})$ of the 3 recordings for each subject. Inter-visit reproducibility was assessed using Bland-Altman analysis ${ }^{20}$ and intra-class correlation coefficient (ICC). ICC was calculated using SPSS (version 22, IBM SPSS inc, Armonk, NY, USA) using a 2-way mixed analysis of absolute agreement. For the comparison of MBW methods, outcomes were compared using a paired $t$-test and the agreement between the 2 systems assessed using BlandAltman analysis. ${ }^{20}$ Significance level was set at $p=0.05$.

\section{Results}

Fifty-four patients diagnosed with COPD (37 male) performed assessment of lung function and MBW. Mean (SD) age of subjects was 66 (7) years, with a median smoking history of 42 pack-years (full demographics presented in Table 1). Seventeen (31\%) of the COPD patients were frequent exacerbators, defined as having $\geq 2$ exacerbations in the last 12 months.

\section{Practicality of $\mathrm{MBW}_{\mathrm{N} 2}$}

Four out of the 54 patients diagnosed with COPD (7\%) were unable to complete $\mathrm{MBW}_{\mathrm{N} 2}$ due to leak at the mouthpiece, dry throat, or a sensation of dyspnea when breathing highflow $\mathrm{O}_{2}$. Nine repeat measurements were discarded for failure to meet quality control criteria. Patients with high minute
Table I Clinical characteristics and lung function measurements

\begin{tabular}{|c|c|c|}
\hline \multirow[t]{2}{*}{ Clinical characteristics } & \multicolumn{2}{|l|}{ COPD $(n=54)$} \\
\hline & Absolute values & $\%$ predicted \\
\hline Sex (male/female) & $37 / 17$ & \\
\hline Age (years) & $66(7)$ & \\
\hline Height (m) & $1.67(0.10)$ & \\
\hline Weight (kg) & $78.8(18.6)$ & \\
\hline Body mass index $\left(\mathrm{kg} / \mathrm{m}^{2}\right)$ & $27.8(4.9)$ & \\
\hline Smoking history (pack years) ${ }^{\mathrm{a}}$ & $42.1(31.7-55.5)$ & \\
\hline \multicolumn{3}{|l|}{ Spirometry } \\
\hline $\mathrm{FEV}_{1}(\mathrm{~L})$ & $1.68(0.6)$ & $63.1(18.4)$ \\
\hline $\mathrm{FEF}_{25 \%-75 \%}(\mathrm{~L} / \mathrm{s})$ & $0.66(0.35)$ & $22.0(11.2)$ \\
\hline $\mathrm{FVC}(\mathrm{L})$ & $3.62(1.0)$ & $106.6(17.8)$ \\
\hline $\mathrm{FEV}_{1} / \mathrm{FVC}$ & $0.48(0.13)$ & \\
\hline \multicolumn{3}{|c|}{ Multiple breath nitrogen washout } \\
\hline $\mathrm{MBW}_{\mathrm{N} 2}$ test time (mins) & $38.4(19.9)$ & \\
\hline $\mathrm{FRC}_{\mathrm{N} 2}(\mathrm{~L})$ & $4.35(1.27)$ & I $35.7(36.8)$ \\
\hline $\mathrm{LCI}_{\mathrm{N} 2}$ & I2.I (2.2) & I58.9 (29.3) \\
\hline \multicolumn{3}{|l|}{ Plethysmography } \\
\hline TLC (L) & $6.30(1.27)$ & $105.5(15.4)$ \\
\hline Inspiratory capacity (L) & $2.15(0.59)$ & $78.4(15.2)$ \\
\hline $\mathrm{FRC}_{\text {pleth }}(\mathrm{L})$ & $3.99(1.06)$ & $123.0(29.8)$ \\
\hline $\mathrm{RV}(\mathrm{L})$ & $2.95(0.97)$ & $127.9(40.7)$ \\
\hline RV/TLC \% & $46.6(10.5)$ & \\
\hline \multicolumn{3}{|l|}{ Gas transfer } \\
\hline $\mathrm{DL}_{\mathrm{CO}}\left(\mathrm{mmol} \cdot \mathrm{min}^{-1} \cdot \mathrm{kPa}^{-1}\right)$ & $5.23(1.78)$ & $63.1(18.4)$ \\
\hline $\mathrm{K}_{\mathrm{cO}}\left(\mathrm{mmol} \cdot \mathrm{min}^{-1} \cdot \mathrm{kPa}^{-1}\right)$ & $\mathrm{I} .07(0.28)$ & $79.6(23.2)$ \\
\hline \multicolumn{3}{|l|}{ Forced oscillation } \\
\hline $\mathrm{R}_{5}-\mathrm{R}_{20}{ }^{\mathrm{a}}(\mathrm{kPa} / \mathrm{L} / \mathrm{s})$ & $0.17(0.11-0.25)$ & \\
\hline $\mathrm{X}_{5}(\mathrm{kPa} / \mathrm{L} / \mathrm{s})$ & $-0.30(0.16)$ & \\
\hline CAT score ${ }^{a}$ & I8.0 (9.0-25.3) & \\
\hline
\end{tabular}

Note: Parametric data are expressed as mean and SD except ${ }^{a}$ median and interquartile range.

Abbreviations: CAT, COPD Assessment Test; $\mathrm{DL}_{\mathrm{co}}$, carbon monoxide diffusing capacity; FEF, forced expiratory flow; FEV , forced expiratory volume in I second; FRC, functional residual capacity; $F R C_{\mathrm{N} 2}$, FRC measured by nitrogen washout; $F R C_{\text {pleth' }}, F R C$ measured by plethysmography; $F V C$, forced vital capacity; $K_{\mathrm{co}}$, carbon monoxide transfer coefficient; $\mathrm{LCl}_{\mathrm{N} 2}$, lung clearance index measured by nitrogen washout; $\mathrm{MBW}_{\mathrm{N} 2}$, multiple-breath washout using nitrogen; RV, residual volume; TLC, total lung capacity.

ventilation would sometimes re-inspire expired air or room air from the end of the flow-past circuit. Overall, success rate was similar to that achieved for the other physiological assessments (Table S1). Median (IQR) total test time in COPD patients was 36.3 (23.8-44.9) minutes. Test time increased in those with higher LCI, $r^{2}=0.24, p=0.0006$ (Figure S1).

\section{Repeatability and reproducibility of $M B W$ in COPD}

The median (IQR) intra-test $\mathrm{CV}$ of triplicate repeat $\mathrm{FRC}_{\mathrm{N} 2}$ measurements on the same visit was $4.3(1.7-6.3)$ for FRC and 4.1 (2.2-7.1) for LCI.

Twenty clinically stable patients diagnosed with COPD performed repeat measurements of $\mathrm{MBW}_{\mathrm{N} 2}$ in triplicate after a mean (SD) interval of 16 (13) days. There was a mean difference in $\mathrm{FRC}_{\mathrm{N} 2}$ between visits of $-0.4 \%$ predicted (absolute), 
$95 \%$ limits of agreement $-28.9 \%$ to $28.1 \%$ (Figure S2). ICC for repeat FRC was 0.90 (95\% CI: $0.76-0.96)$. For $\mathrm{LCI}_{\mathrm{N} 2}$, the mean difference between visits was -0.11 with limits of agreement -1.79 to 1.59 , approximately equivalent to $\pm 15 \%$ of initial LCI (Figure S3). ICC for LCI was 0.94 (95\% CI: 0.86-0.98).

\section{Comparison of $\mathrm{LCl}$ with other lung physiology assessments}

$\mathrm{LCI}_{\mathrm{N} 2}$ was raised in all patients with COPD (Z-score >1.65), including $10(20 \%$ of the COPD patients) with GOLD stage 1 (defined as $\mathrm{FEV}_{1}>80 \%$ predicted). ${ }^{21} \mathrm{LCI}_{\mathrm{N} 2}$ showed significant inverse correlation with $\mathrm{FEV}_{1} \mathrm{Z}$-score $\left(r^{2}=0.36\right.$, $p<0.0001$; Figure 1) and forced expiratory flow (FEF) ${ }_{25 \%-75 \%}$ $\left(r^{2}=0.36, p<0.0001\right) . \mathrm{LCI}_{\mathrm{N} 2}$ also showed significant positive correlations with $\mathrm{R}_{5}-\mathrm{R}_{20}\left(r^{2}=0.17, p=0.009\right)$, residual volume/ total lung capacity (RV/TLC [\%]) $\left(r^{2}=0.16, p=0.02\right), \mathrm{R}_{\text {aw }}$ $\left(r^{2}=0.30, p=0.0006\right)$, and significant negative correlations with $\mathrm{X}_{5}\left(r^{2}=0.35, p=0.0006\right), \mathrm{sG}_{\mathrm{aw}}\left(r^{2}=0.18, p=0.012\right)$ and $\mathrm{DL}_{\mathrm{CO}}\left(r^{2}=0.34, p=0.0001\right)$. There was no correlation between $\mathrm{LCI}_{\mathrm{N} 2}$ and 6MWT distance. Full details of these correlations are presented in Table S2 and Figures S4- $\underline{\mathrm{S} 11}$.

$\mathrm{LCI}_{\mathrm{N} 2}$ also increased significantly with greater GOLD stage. Mean (SD) $\mathrm{LCI}_{\mathrm{N} 2}$ in GOLD stage 1 was 10.2 (1.2), versus GOLD stage $2\left(\mathrm{FEV}_{1} 50 \%-80 \%\right), 11.9(1.8) p=0.048$, or GOLD stage $3\left(\mathrm{FEV}_{1} 30 \%-50 \%\right), 14.19$ (2.3) $p<0.0001$

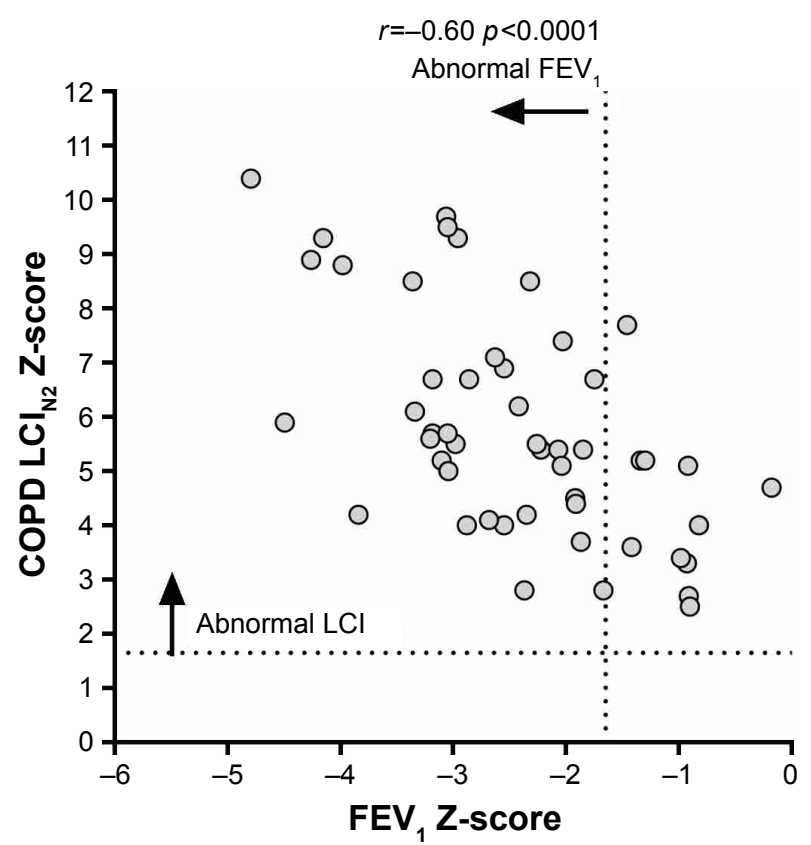

Figure I COPD LCI ${ }_{\mathrm{N} 2}$ Z-score versus FEV, Z-score.

Notes: Z-scores were calculated using the GLI 2012 reference equations for $\mathrm{FEV}_{1}{ }^{17}$ and those provided by Ecomedics for $\mathrm{LCl}$. The horizontal dotted line represents the upper limit of normal for $\mathrm{LCl}_{\mathrm{N} 2}$. The vertical dotted line represents the $\mathrm{FEV}, \mathrm{Z}$-score of -1.65 (lower limit of normal range).

Abbreviations: $\mathrm{FEV}_{1}$, forced expiratory volume in I second; GLI, global lung initiative; $\mathrm{LCl}_{\mathrm{N} 2}$, lung clearance index measured by nitrogen washout.

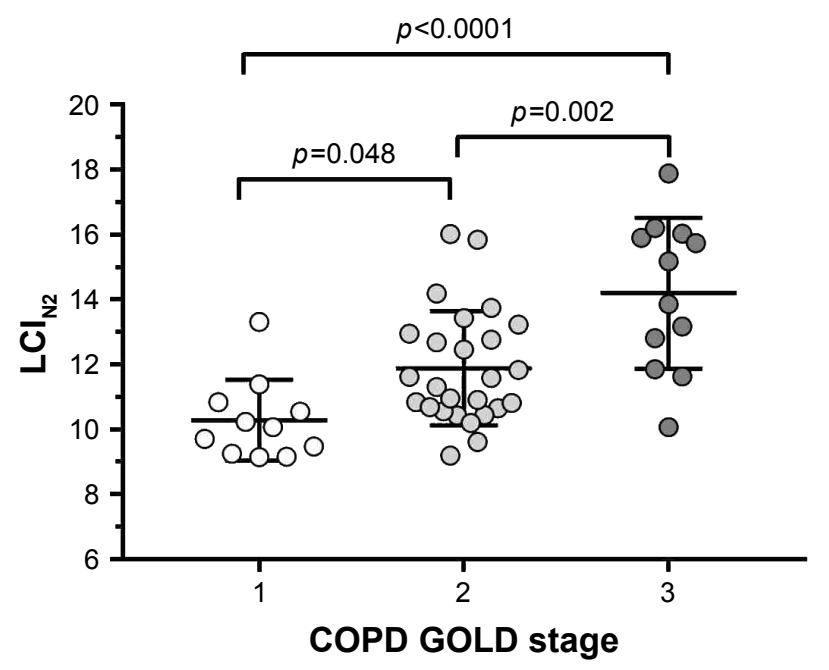

Figure $2 \mathrm{LCl}_{\mathrm{N} 2}$ versus COPD GOLD stage.

Abbreviations: GOLD, Global Initiative for Obstructive Lung Disease; $\mathrm{LCI}_{\mathrm{N} 2}$, lung clearance index measured by nitrogen washout

(Figure 2). There was only a single subject with GOLD stage 4 COPD, omitted from this analysis. Difference between lung physiology outcomes for the different GOLD stages $(1-3)$ is presented in the OLS (Table S3). In addition to LCI, there was statistically significant separation between all 3 GOLD stages for $\mathrm{sG}_{\text {aw }}$ and $\mathrm{FEF}_{25 \%-75 \%}$.

\section{Comparison of FRC assessments}

Seventeen patients diagnosed with COPD completed separate sequential assessments of FRC and LCI using both $\mathrm{N}_{2}$ and $\mathrm{SF}_{6}$ as the washout gases (Table 2). There was no significant difference in LCI measured by sulphur hexafluoride washout $\left(\mathrm{LCI}_{\mathrm{SF} 6}\right)$ and $\mathrm{LCI}_{\mathrm{N} 2}(11.9$ [3.1] versus 12.3 [2.2], $p=0.4)$.

Table 2 Clinical characteristics and lung function measurements of COPD patients with paired MBW assessments

\begin{tabular}{|c|c|c|}
\hline Clinical parameter & COPD $(n=\mid 7)$ & $p$-value \\
\hline \multicolumn{3}{|l|}{ FRC (L) } \\
\hline $\begin{array}{l}\mathrm{FRC}_{\mathrm{N} 2} \\
\mathrm{FRC}_{\mathrm{SEG}}\end{array}$ & $\begin{array}{l}4.24(1.47) \\
3.49(1.00)\end{array}$ & 0.002 \\
\hline \multicolumn{3}{|l|}{ FRC (\%) predicted } \\
\hline $\begin{array}{l}\mathrm{FRC}_{\mathrm{N} 2} \\
\mathrm{FRC}\end{array}$ & $\begin{array}{l}\text { I } 36.8(42.8) \\
\text { | I } 2.4(28.0)\end{array}$ & 0.002 \\
\hline \multicolumn{3}{|l|}{ Lung clearance index } \\
\hline $\begin{array}{l}\mathrm{LCl}_{\mathrm{N} 2} \\
\mathrm{LCl}_{\mathrm{SF} 6}\end{array}$ & $\begin{array}{l}12.3(2.2) \\
11.9(3.1)\end{array}$ & \multirow[t]{4}{*}{0.4} \\
\hline $\mathrm{FEV}_{1}(\%)$ & $64.2(21.1)$ & \\
\hline FVC (\%) & $101.4(13.6)$ & \\
\hline $\mathrm{FEV} / \mathrm{FVC}$ & $0.5(0.1)$ & \\
\hline
\end{tabular}

Note: Parametric data are expressed as mean and SD, and comparisons were performed using Student's $t$-test.

Abbreviations: FEV , forced expiratory volume in I second; FVC, forced vital capacity; $\mathrm{FRC}$, functional residual capacity; $\mathrm{FRC}_{\mathrm{N} 2}, \mathrm{FRC}$ measured by nitrogen washout; $\mathrm{FRC}_{\mathrm{SF} 6}$, $\mathrm{FRC}$ measured by sulphur hexafluoride washout; $\mathrm{LCl}_{\mathrm{N} 2}$, lung clearance index measured by nitrogen washout; $\mathrm{LCl}_{\mathrm{SFF}}$, lung clearance index measured by sulphur hexafluoride washout; MBW, multiple-breath washout. 


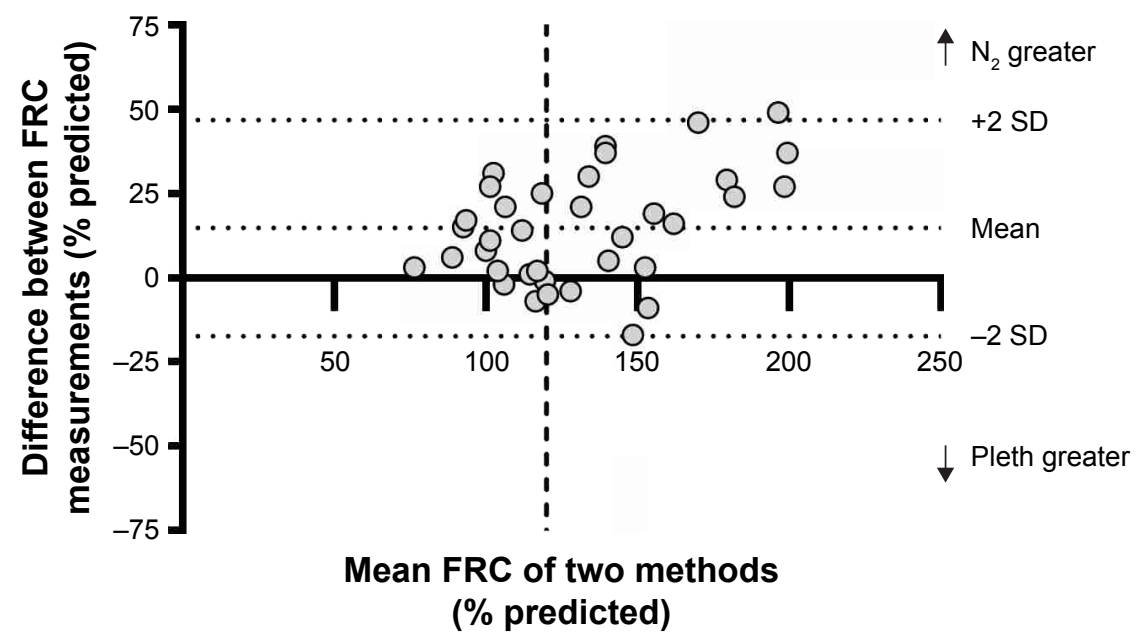

Figure 3 Bland-Altman comparison between $\mathrm{FRC}_{\mathrm{N} 2}$ and $\mathrm{FRC}_{\text {pleth }}$ in subjects with COPD.

Notes: The central dotted line represents the mean difference, and the upper and lower dotted lines represent the limits of agreement. The vertical line represents hyper-inflation, defined as $\mathrm{FRC}_{\mathrm{N} 2}>120 \%$ predicted. Data points plotted above the x-axis represent subjects in which $\mathrm{FRC}_{\mathrm{N} 2}$ was greater than $\mathrm{FRC}_{\text {pleth }}$

Abbreviations: $F R C$, functional residual capacity; $F C_{N 2}, F R C$ measured by nitrogen washout; $F R C_{\text {pleth }}$, FRC measured by plethysmography.

$\mathrm{FRC}_{\mathrm{N} 2}$, however, was significantly elevated compared with FRC measured by sulphur hexafluoride washout $\left(\mathrm{FRC}_{\mathrm{SF} 6}\right)$. Mean (SD) of $\mathrm{FRC}_{\mathrm{N} 2}$ was 136.8 (42.8) \% predicted compared with 112.4 (28.0) \% for $\mathrm{FRC}_{\mathrm{SF} 6}, p=0.002$. The difference between $\mathrm{FRC}_{\mathrm{N} 2} \%$ and $\mathrm{FRC}_{\mathrm{SF} 6} \%$ increased disproportionally as $\mathrm{FRC} \%$ increased. The mean difference was 24.4 (26.4) \% predicted with limits of agreement -27.3 to $76.1 \%$ predicted (Figure S12).

FRC values measured by plethysmography and nitrogen washout were also compared for the whole cohort at visit 1 . Overall, $\mathrm{FRC}_{\mathrm{N} 2}$ was significantly greater than $\mathrm{FRC}$ measured by plethysmography $\left(\mathrm{FRC}_{\text {pleth }}\right)(139.3 \%$ versus $124.5 \%$, $p<0.0001)$. Mean difference between $\mathrm{FRC}_{\mathrm{N} 2}$ and $\mathrm{FRC}_{\text {pleth }}$ was $14.8 \%$ predicted (limits of agreement -17.3 to 46.8 ; Figure 3), with a disproportionate increase in $\mathrm{FRC}_{\mathrm{N} 2}$ in those with higher FRC \% predicted.

\section{Discussion}

This is the first study to compare different MBW techniques, alongside detailed physiological phenotyping, in patients diagnosed with COPD. The specific objectives were to understand more about the repeatability and practical limitations of MBW in COPD. This study found LCI to be sensitive to detect mild COPD, being elevated even in those in GOLD stage 1. Intra-visit repeatability was similar to that reported in CF studies ${ }^{8,13}$ and inter-visit reproducibility was similar to that of CF adults. ${ }^{22}$ Finally, LCI has physiologically valid correlations with other small airways measurements (including $\mathrm{X}_{5}, \mathrm{R}_{5}-\mathrm{R}_{20}, \mathrm{RV} / \mathrm{TLC}, \mathrm{R}_{\mathrm{aw}}$ ) as well as other markers of COPD severity, such as $\mathrm{DL}_{\mathrm{CO}}$. This accords with recent work showing that smokers with preserved $\mathrm{FEV}_{1}$ had evidence of small airways damage, gas trapping, and impaired gas transfer. ${ }^{23,24}$ Abnormality in single-breath nitrogen washout in symptomatic smokers and in MBW parameters in asymptomatic smokers ( $>10$ pack years) has also been previously demonstrated. ${ }^{24,25}$ The particular advantages of LCI as an outcome for assessing these early changes is that the methodology is standardized, ${ }^{14}$ with good reproducibility, and with apparently good sensitivity. This last feature is harder to quantify, however, since there is no gold-standard definition of COPD that does not involve spirometry. It is nevertheless reassuring that LCI was abnormal (Z-score $>1.65)$ in all the subjects with previously defined COPD and that it appeared to be more sensitive in this regard at detecting early airway change than the other lung physiology assessments. As with severe CF, however, the measurement appears less useful in those with more advanced COPD. In these patients, the test takes much longer to complete and the overall ventilation heterogeneity signal likely reflects a mixed pattern of disease. Thus, any signal from potentially reversible small airways disease will be overwhelmed by the signal from other lung regions where damage is more advanced and irreversible. These data and observations, therefore, support a role for $\mathrm{MBW}$ in measuring disease severity in patients with mildto-moderate (GOLD stage 1-2) COPD, and possibly in detecting disease before it fulfills current spirometry-driven criteria.

An important caveat, however, exists for the specific nitrogen washout system used in this study. An unanticipated finding was that the measures of $\mathrm{FRC}_{\mathrm{N} 2}$ were far greater not only than those of $\mathrm{FRC}_{\mathrm{SF} 6}$ but also $\mathrm{FRC}_{\text {pleth }}$. Plethysmography measures all gas within the thoracic cavity and should, 
therefore, always measure a greater value for "FRC" than that which is ventilated during the quiet tidal breathing of a MBW test. $\mathrm{FRC}_{\text {pleth }}$ and $\mathrm{FRC}_{\mathrm{N} 2}$ are similar in healthy subjects, ${ }^{26}$ but increasing $\mathrm{FRC}_{\text {pleth }}$ should be apparent in disease as gas trapping worsens, leading to an even greater discrepancy between tidally ventilated and total end-expiratory lung volumes. ${ }^{27}$ In this study, however, we have observed the opposite. Although both $\mathrm{FRC}_{\text {pleth }}$ and $\mathrm{FRC}_{\mathrm{N} 2}$ were elevated in $\mathrm{COPD}, \mathrm{FRC}_{\mathrm{N} 2}$ was higher than $\mathrm{FRC}_{\text {pleth }}$ with an offset of almost 20\%. This difference also worsened in those with more severe disease, implying that tidally ventilated lung volume becomes increasingly greater than total lung volume as disease progresses. Clearly, this conclusion cannot be correct.

A recent study compared 2 similar indirect $\mathrm{N}_{2}$ devices (Exhalyzer D versus EasyOne Pro, NDD Medical Technologies, Zurich, Switzerland). A difference of 30\% in FRC values was found between these systems, with the Exhalyzer D generating higher mean values, ${ }^{9}$ consistent with the observations in this study. This suggests an over-reading of FRC by the Exhalyzer system, which may be device-specific. Recent attempts to correct for excretion of body nitrogen did not fully account for this error, ${ }^{28,29}$ and are not included in this analysis. The limitations of this same $\mathrm{MBW}_{\mathrm{N} 2}$ system for measuring lung volumes have also recently been recognized in patients with $\mathrm{CF},{ }^{30}$ and seem to have occurred despite promising in vitro data for this method. ${ }^{7}$ Importantly, accurate FRC measurement is essential for all MBW outcome measurements, including LCI. Reassuringly, however, the $\mathrm{SF}_{6}$ washout gave similar values for LCI despite much lower values for FRC. This may be because both FRC and cumulative expired volume are overestimated to the same extent with the nitrogen washout, but importantly suggests no loss of sensitivity by using $\mathrm{SF}_{6}$.

In this study, we have assessed patients diagnosed with COPD over a wide range of severity, including at repeat time points. The lack of a simple positive control for COPD, however, means that we cannot easily assess what the response to therapy should be. We also did not include a healthy control population, but have instead used the reference data from previous age-matched cohorts provided by the manufacturer to calculate Z-scores. LCI was assessed on site, using the on-board software of the Exhalyzer-D device. Measurements were not subject to external over-read as recently recommended in clinical trials, ${ }^{6}$ although the research team has considerable experience with $\mathrm{MBW}$ as a technique.

\section{Conclusion}

We have shown that LCI offers substantial promise as a measurement in COPD. The key practical features of MBW assessment in COPD are similar to those in CF, and LCI appears to work best as a measure of early airways disease in those with well-preserved $\mathrm{FEV}_{1}$. However, the specific nitrogen washout system used here exhibited major limitations in terms of the accuracy of the FRC measurements, something that has not been adequately accounted for and which has significant implications for clinical trials and trial networks already in progress. Considerable caution should, therefore, be employed in interpreting nitrogen washout outcomes until the reasons for this error are better understood.

\section{Acknowledgments}

The authors gratefully thank the patients who kindly took part in this study and acknowledge Paul Hitchen in aiding data collection. This study received no specific grant from funding agencies in the public, commercial, or not-for-profit sectors. AH received funding to support the study from the National Institute of Health Research (NIHRS012-13). This report, therefore, presents independent research funded by the National Institute for Health Research (NIHR). The views expressed are those of the author(s) and not necessarily those of the NHS, the NIHR, or the Department of Health.

\section{Disclosure}

ASB and PJL were supported by the Medicines Evaluation Unit, University Hospital of South Manchester, UK. DS reports personal fees from Apellis, Peptinovate, Skyepharma, Cipla, and Genentech, and grants and personal fees from AstraZeneca, Boehringer Ingleheim, Chiesi, Glenmark, Merck, Mundipharma, Novartis, Pfizer, Pulmatrix, Teva, Therevance and Verona, all outside the submitted work. AH reports personal fees from Celtaxys, Vertex, Chiesi, Boehringer Ingelheim, and collaboration agreement with Innovision ApS, outside the submitted work. The authors report no other conflicts of interest in this work.

\section{References}

1. Horsley A, Siddiqui S. Putting lung function and physiology into perspective: cystic fibrosis in adults. Respirology. 2015;20(1):33-45.

2. Robinson PD, Goldman MD, Gustafsson PM. Inert gas washout: theoretical background and clinical utility in respiratory disease. Respiration. 2009;78(3):339-355.

3. Fleming GM, Chester EH, Saniie J, Saidel GM. Ventilation inhomogeneity ising multibreath nitrogen washout: comparison of moment ratios and other indexes. Am Rev Respir Dis. 1980;121(5):789-794.

4. Verbanck S, Schuermans D, Meysman M, Paiva M, Vincken W. Noninvasive assessment of airway alterations in smokers: the small airways revisited. Am J Respir Crit Care Med. 2004;170(4):414-419.

5. Swift AJ, Wild JM, Fichele S, et al. Emphysematous changes and normal variation in smokers and COPD patients using diffusion $3 \mathrm{He}$ MRI. Eur J Radiol. 2005;54(3):352-358. 
6. Kent L, Reix P, Innes JA, et al; European Cystic Fibrosis Society Clinical Trial Network (ECFS-CTN) Standardisation Committee. Lung clearance index: evidence for use in clinical trials in cystic fibrosis. $J$ Cyst Fibros. 2014;13(2):123-138.

7. Singer F, Houltz B, Latzin P, Robinson P, Gustafsson P. A realistic validation study of a new nitrogen multiple-breath washout system. PLoS One. 2012;7(4):e36083.

8. Jensen R, Stanojevic S, Gibney K, et al. Multiple breath nitrogen washout: a feasible alternative to mass spectrometry. PLoS One. 2013 8(2):e56868.

9. Poncin W, Singer F, Aubriot AS, Lebecque P. Agreement between multiple-breath nitrogen washout systems in children and adults. J Cyst Fibros. 2017;16(2):258-266.

10. Huque MF, Alosh M, Bhore R. Addressing multiplicity issues of a composite endpoint and its components in clinical trials. $J$ Biopharm Stat. 2011;21(4):610-634.

11. Fuchs SI, Ellemunter H, Eder J, et al. Feasibility and variability of measuring the Lung Clearance Index in a multi-center setting. Pediatr Pulmonol. 2012;47(7):649-657.

12. Vestbo J, Hurd SS, Agusti AG, et al. Global strategy for the diagnosis, management, and prevention of chronic obstructive pulmonary disease: GOLD executive summary. Am J Respir Crit Care Med. 2013;187(4): 347-365

13. Horsley AR, Gustafsson PM, Macleod KA, et al. Lung clearance index is a sensitive, repeatable and practical measure of airways disease in adults with cystic fibrosis. Thorax. 2008;63(2):135-140.

14. Robinson PD, Latzin P, Verbanck S, et al. Consensus statement for inert gas washout measurement using multiple- and single- breath tests. Eur Respir J. 2012;41(3):507-522.

15. Miller MR, Hankinson J, Brusasco V, et al; ATS/ERS Task Force. Standardisation of spirometry. Eur Respir J. 2005;26(2):319-338.

16. Wanger J, Clausen JL, Coates A, et al. Standardisation of the measurement of lung volumes. Eur Respir J. 2005;26(3):511-522.

17. Oostveen E, MacLeod D, Lorino H, et al; ERS Task Force on Respiratory Impedance Measurements. The forced oscillation technique in clinical practice: methodology, recommendations and future developments. Eur Respir J. 2003;22(6):1026-1041.

18. Macintyre N, Crapo RO, Viegi G, et al. Standardisation of the single-breath determination of carbon monoxide uptake in the lung. Eur Respir J. 2005;26(4):720-735.
19. Crapo RO, Enright PL, Zeballos RJ; ATS Committee on Proficiency Standards for Clinical Pulmonary Function Laboratories. American Thoracic Society Statement: guidelines for the six-minute walk test. Am J Respir Crit Care Med. 2002;166(1):111-117.

20. Bland JM, Altman DG. Statistical methods for assessing agreement between two methods of clinical measurement. Lancet. 1986; 1(8476):307-310.

21. Vogelmeier CF, Criner GJ, Martinez FJ, et al. Global strategy for the diagnosis, management, and prevention of chronic obstructive lung disease 2017 report. GOLD executive summary. Am J Respir Crit Care Med. 2017;195(5):557-582.

22. Horsley A, Shawcross A, Oladapo M, et al. P255 Reproducibility of lung clearance index (LCI) in clinically stable adults with mild cystic fibrosis (CF). Thorax. 2016;71:A226.

23. Elbehairy AF, Faisal A, Guenette JA, et al; Canadian Respiratory Research Network (CRRN). Resting physiological correlates of reduced exercise capacity in smokers with mild airway obstruction. COPD. 2017; 14(3):267-275.

24. Di Marco F, Terraneo S, Job S, et al. Cardiopulmonary exercise testing and second-line pulmonary function tests to detect obstructive pattern in symptomatic smokers with borderline spirometry. Respir Med. 2017; 127:7-13.

25. Verbanck S, Schuermans D, Meysman M, Paiva M, Vincken W. Noninvasive assessment of airway alterations in smokers: the small airways revisited. Am J Respir Crit Care Med. 2004;170(4):414-419.

26. Dubois AB, Botelho SY, Bedell GN, Marshall R, Comroe JH Jr. A rapid plethysmographic method for measuring thoracic gas volume: a comparison with a nitrogen washout method for measuring functional residual capacity in normal subjects. J Clin Invest. 1956;35(3):322-326.

27. Coates AL, Peslin R, Rodenstein D, Stocks J. Measurement of lung volumes by plethysmography. Eur Respir J. 1997;10(6):1415-1427.

28. Nielsen N, Nielsen JG, Horsley AR. Evaluation of the impact of alveolar nitrogen excretion on indices derived from multiple breath nitrogen washout. PLoS One. 2013;8(9):e73335.

29. Kane M, Rayment JH, Jensen R, McDonald R, Stanojevic S, Ratjen F. Correcting for tissue nitrogen excretion in multiple breath washout measurements. PLoS One. 2017;12(10):e0185553.

30. Bayfield KJ, Saunders C, Alton EWFW, Davies JC. Comparison of CF and Non CF LCI results using the Exhalyzer D and Innocor ${ }^{\mathrm{TM}}$ devices. Thorax. 2015;70(Suppl 3):A115.
International Journal of COPD

\section{Publish your work in this journal}

The International Journal of COPD is an international, peer-reviewed journal of therapeutics and pharmacology focusing on concise rapid reporting of clinical studies and reviews in COPD. Special focus is given to the pathophysiological processes underlying the disease, intervention programs, patient focused education, and self management protocols.

\section{Dovepress}

This journal is indexed on PubMed Central, MedLine and CAS. The manuscript management system is completely online and includes a very quick and fair peer-review system, which is all easy to use. Visit http://www.dovepress.com/testimonials.php to read real quotes from published authors. 